\title{
Band-Notched Characteristic using Meandered Ground Stubs for Compact UWB Antennas
}

\author{
Y. F. Weng, S. W. Cheung and T. I. Yuk \\ Department of Electrical and Electronic Engineering \\ The University of Hong Kong, Hong Kong \\ E-mail: [yfweng, swcheung, tiyuk]@eee.hku.hk
}

\begin{abstract}
In this paper, a pair of meandered ground stubs is used to design a single band-notched characteristic in a compact planar-monopole antenna for ultrawide band (UWB) applications. The single-band notch covers the wireless area network (WLAN) band from 5.15 GHz to $5.825 \mathrm{GHz}$. The centernotch frequency and notch bandwidth can be adjusted using the dimensions of the meandered ground stubs. Prototype of the proposed antenna is designed, fabricated and studied. The bandnotched characteristics, return loss, radiation patterns, peak gains and efficiencies of the antenna are studied using both computer simulation and measurements.
\end{abstract}

Keywords - monopole antenna, ultrawideband (UWB) antenna, band notched, meandered ground stub.

\section{INTRODUCTION}

More and more attention has been attracted to ultrawideband (UWB) communication systems since the US-FCC allocated the frequency band of $3.1-10.6 \mathrm{GHz}$ in 2002 [1], and many emerging microwave technologies and applications are operating on UWB band. In most UWB applications such as PCs, high-definition TVs and digital cameras etc., compact and low cost UWB antennas with non-dispersive, omnidirectional radiation pattern and relatively uniform gain are desirable. Planar monopole antennas with the merits of low-profile, ease of fabrication on printed circuit boards, and ease of integration with other RF components, are more favorable to the traditional 3-D antennas for compact UWB applications.

UWB communication systems operating in such a wide frequency band could easily be affected by the nearby communication systems such as the IEEE 802.11a WLAN from $5.15 \mathrm{GHz}$ to $5.825 \mathrm{GHz}$ in the US [2]. The interference levels emitted by the WLAN systems can be suppressed by using band-stop filters, but this will increase the cost and system complexity and require more space when integrated with other microwave circuits. One possible solution to this problem is to design the UWB antennas with band-notched characteristics. Different design methods have been proposed to implement the band-notched characteristic for UWB planar monopole antennas [3-15], e.g. using parasitic elements [4], folded strips [5], split-ring resonators (SRRs) [6-7], quarter wavelength tuning stubs [8], meandered ground stubs [9], resonated cells on the microstrip feed line or coplanar waveguide (CPW) [10] fractal structure [11] and slots on the radiator [12-13]. When a current is flowing on a microstrip line, it mainly distributes on the edges of the microstrip line. Thus to implement the notches for antennas, an effective way is to place resonators (or filters) along the feed line of the antennas [14-15]. However, for compact UWB antennas, it is difficult to accommodate the large-size half or quarter wavelength resonators.

In this paper, we propose to use a pair of meandered ground stubs along the feed line to realize a single band-notched characteristic for a compact UWB monopole antenna. The design is studied using the computer simulation tool CST MWS and the Satimo Starlab measurement system. The UWB antenna has a single notch covering the WLAN band at a center frequency of $5.5 \mathrm{GHz}$. Results show that the proposed UWB antenna has an operating frequency range from 2.76 $\mathrm{GHz}$ to over $12 \mathrm{GHz}$ with return loss $\geqslant 10 \mathrm{~dB}$ which fully satisfies the requirement for UWB applications. The simulated and measured results on the radiation patterns, peak gains and efficiencies agree well.

\section{ANTENNA DESIGN}

\section{Structure of the single band-notched UWB antenna}

In our UWB antenna design, we propose to use the planarmonopole technology to achieve a compact size for applications in wireless devices. The UWB antenna consists of an elliptical radiator fed by a $50-\Omega$ microstrip line and a rectangular ground plane below the substrate, as shown in Fig. 1. A pair of meandered stubs as shown in Fig. 1 (c), each having a size of $0.0715 \lambda \times 0.0349 \lambda$ at $5.5 \mathrm{GHz}$, is symmetrically placed at a distance of $w_{3}$ from the microstrip feed line and connected to ground through vias. The antenna is fabricated on a PTFE substrate PCB with a transverse dimension of $30 \mathrm{~mm} \times 39.3 \mathrm{~mm}$, a relative dielectric constant $\varepsilon_{r}=3.5$, a thickness $0.8 \mathrm{~mm}$ and a loss tangent 0.003 . The width of the microstrip feed-line changes gradually, from $w_{l}=$ $1.73 \mathrm{~mm}$ near to the feed point to $w_{2}=0.6 \mathrm{~mm}$ near to the radiator, for good impedance matching. The distance between the elliptical radiator and the upper edge of ground, gap, is also quite critical for impedance matching and so has been optimized, using the computer simulation software tool CST MWS, to be $0.3 \mathrm{~mm}$. Detailed dimensions of the single bandnotched antenna are listed in Table 1. 


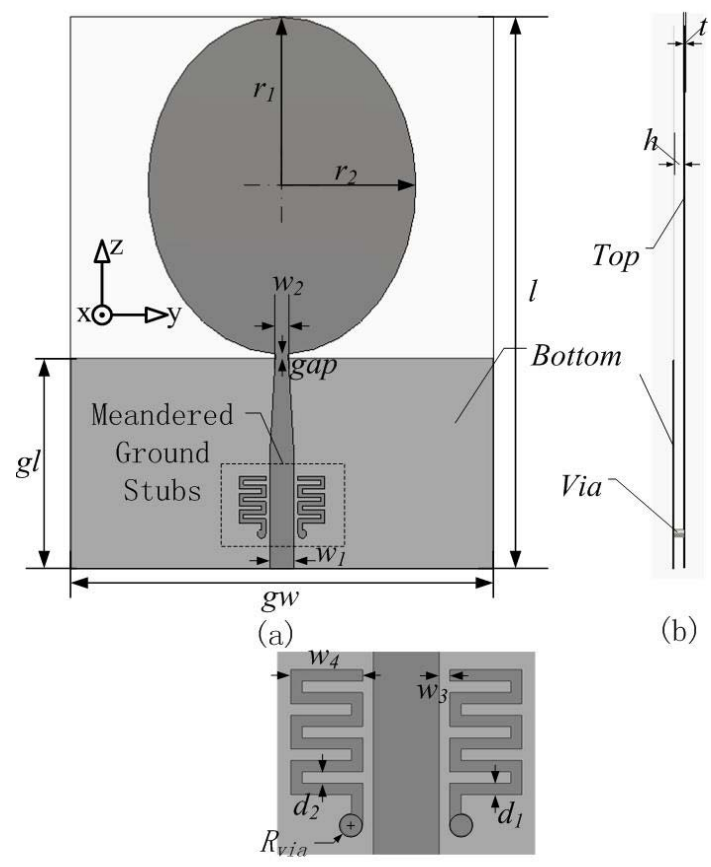

(c)

Fig. 1 Structure of proposed band notched antenna. (a) top view, (b) side view and (c) meandered ground stubs.

TABLE I. SINGLE BAND-NOTCHED ANTENNA DIMENSIONS

\begin{tabular}{cccc}
\hline Parameter & Value $(\mathbf{m m})$ & Parameter & Value(mm) \\
\hline$g l$ & 15 & $w_{1}$ & 1.73 \\
$g w$ & 30 & $w_{2}$ & 0.6 \\
$l$ & 39.3 & $w_{3}$ & 0.4 \\
$r_{1}$ & 12 & $w_{4}$ & 1.9 \\
$r_{2}$ & 9 & $d_{1}$ & 0.3 \\
$t$ & 0.035 & $d_{2}$ & 0.3 \\
$H$ & 0.762 & $R_{\text {via }}$ & 0.4 \\
$g a p$ & 0.3 & & \\
\hline
\end{tabular}

\section{Parametric study of single band-notched UWB antenna}

A parametric study of the single band-notched UWB antenna has been conducted by computer simulation to explore how the dimensions of the meandered ground stubs affect the performance of band notch. Results have shown that the meandered stubs act like resonators. At resonance, the energy is coupled from the feed line to the meandered stubs and then flows to ground through vias. This stops the energy on the feed line from flowing into the elliptical radiator and radiating to free space. The width $d_{1}$ and length $w_{4}$ of the stubs in Fig. 1(c) determine the inductance of the resonators, i.e., the meandered ground stubs. The distances, $d_{2}$ and $w_{3}$, between the meandered stubs and between the feed line and stubs, respectively, determine the capacitance of the resonators.

Computer simulation results on the effects of $d_{1}, w_{3}$ and $w_{4}$ on the return loss of the antenna are shown in Figs. 2-4, respectively. It can be seen that $d_{1}$ and $w_{3}$ determine the center notch frequency and $w_{4}$ mainly affects the notch bandwidth. These plots also reveal that when the values of $d_{1}, w_{3}$ and $w_{4}$ are changed, the return loss in the rest of the UWB band remain about the same. These properties provide the designers with a great freedom to select the notched-band frequency and bandwidth for the antenna.

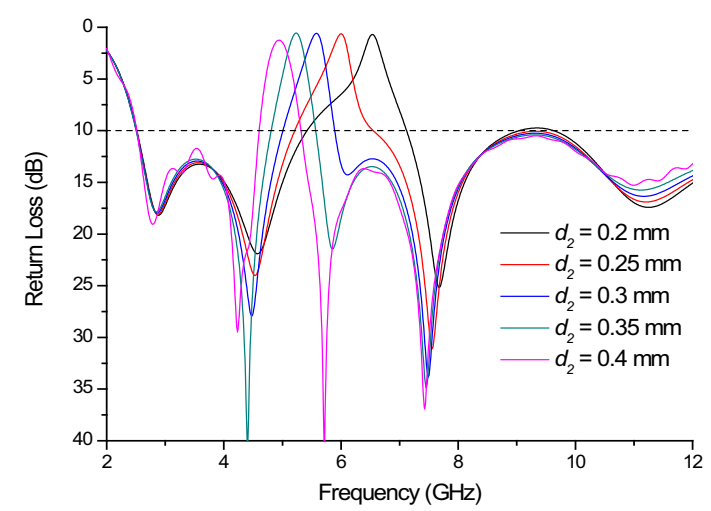

Fig. 2 Return loss for different values of $d_{l}$ with other dimensions fixed.

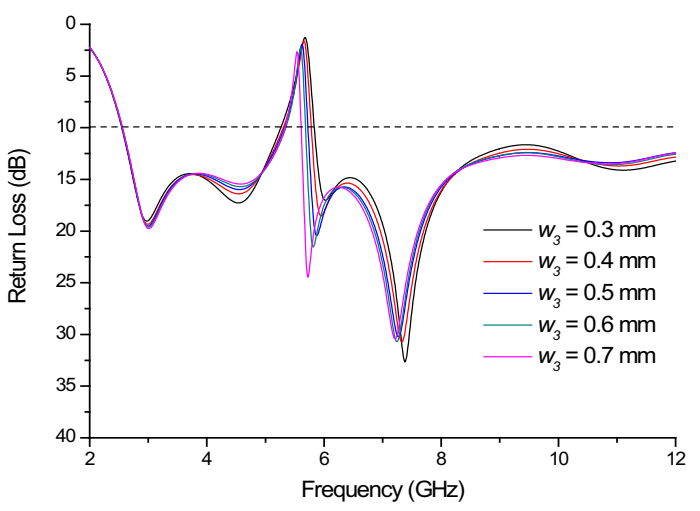

Fig. 3 Return loss for different values of $w_{3}$ with other dimensions fixed.

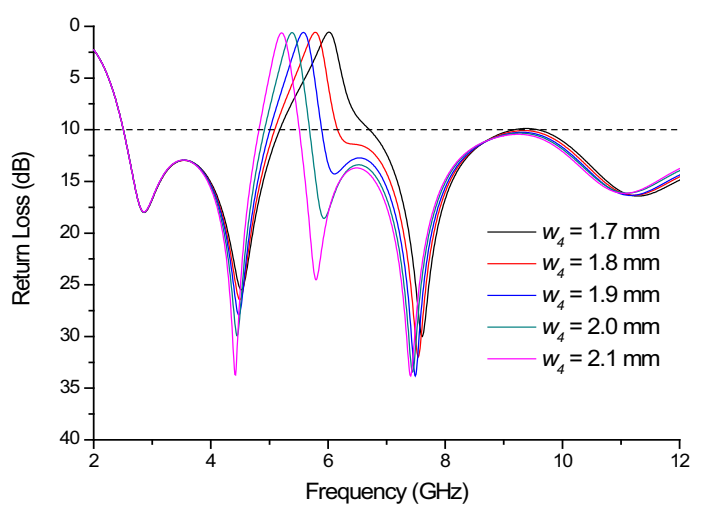

Fig. 4 Return loss for different values of $w_{4}$ with other dimensions fixed.

The surface current distributions of the single band-notched antenna at the frequencies of 4, 5.5, 7 and $10 \mathrm{GHz}$, have also been studied using computer simulation. Figures $5(a), 5(c)$ and 5(d) show that, at the frequencies of 4, 7 and $10 \mathrm{GHz}$, majority of the current can flow through the microstrip feed line into the radiator and eventually get radiated to the free space. There is very little energy coupled to the meandered ground stubs. However, at $5.5 \mathrm{GHz}$, most of the energy is coupled to and confined in the meandered ground stubs. As a result, the current cannot get through the microstrip feed line into the radiator and so does not get radiated by the main radiator. 


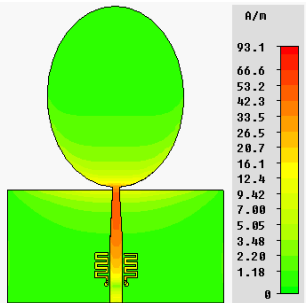

(a)

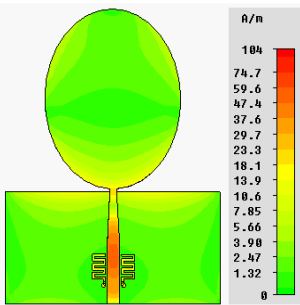

(c)

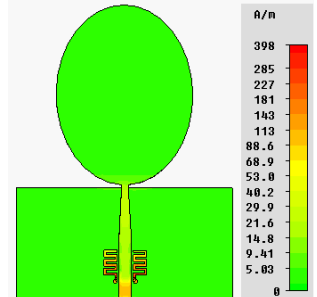

(b)

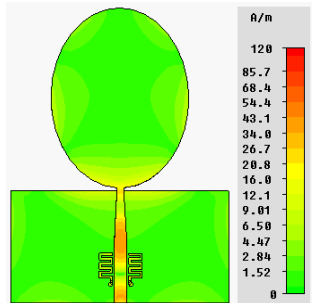

(d)
Fig. 5 Surface current distribution of the proposed band-notched antenna at (a) $4 \mathrm{GHz}$, (b) $5.5 \mathrm{GHz}$ (c) $7 \mathrm{GHz}$ and (d) $10 \mathrm{GHz}$.

\section{RESUlTS AND DISCUSSIONS}

The design of our band-notched antenna has been fabricated using a PCB with PTFE substrate as shown in Fig. 6. The return loss, peak gains and efficiencies across the UWB band, and the radiation patterns at 4, 5.5, 7 and $10 \mathrm{GHz}$ have been simulated using the CST MWS and measured using the Satimo Starlab measurement system.

The simulated and measured return loss of the antennas are shown in Fig. 7. It can be seen that, the antenna can operate from $2.76 \mathrm{GHz}$ to over $12 \mathrm{GHz}$ with return loss $\geqslant 10 \mathrm{~dB}$ which fully satisfies the UWB requirement. In the WLAN band from 4.98 to $5.93 \mathrm{GHz}$, the measured return loss are substantially lower than $10 \mathrm{~dB}$.

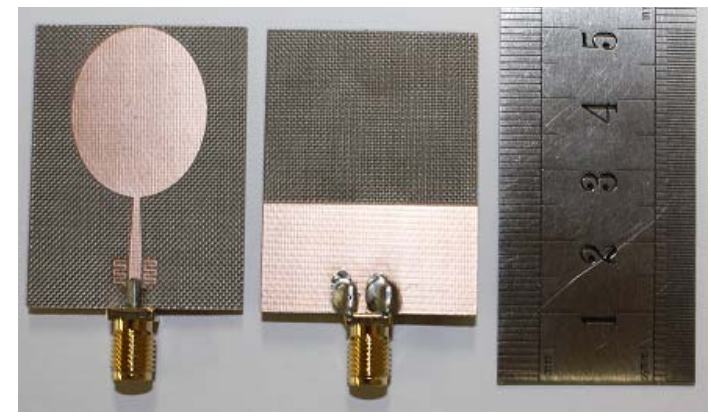

Fig. 6 Photograph of proposed single band-notched antenna.

The simulated and measured radiation patterns of the antenna at the frequencies of $4,5.5,7$ and $10 \mathrm{GHz}$ in the two principle planes, $x-y$ and $x-z$ planes, are shown in Fig. 8. At 4, 7 and $10 \mathrm{GHz}$, Fig. 8(a), 8(e) and 8(g) show that the antenna has approximately omnidirectional radiation patterns in $x-y$ plane. In the $\mathrm{x}-\mathrm{z}$ plane patterns, Figs. $8(\mathrm{~b}), 8(\mathrm{f})$ and $8(\mathrm{~h})$ show that there are two nulls at $\mathrm{z}$ direction. This is similar to that of a typical monopole antenna. The radiation patterns in Figs. 8(c) and $8(\mathrm{~d})$ for $5.5 \mathrm{GHz}$ indicate that the gains are almost evenly suppressed in all directions by the pair of meandered ground stubs and the average gain is about $-10 \mathrm{dBi}$.

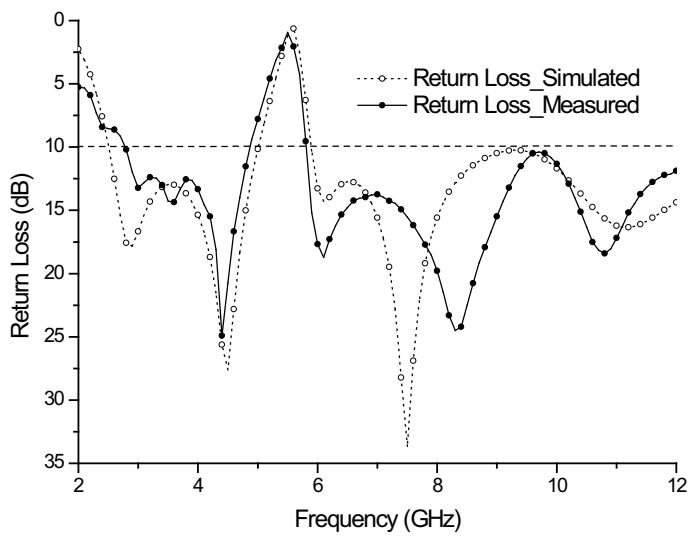

Fig. 7 Simulated and measured return loss of proposed antenna.
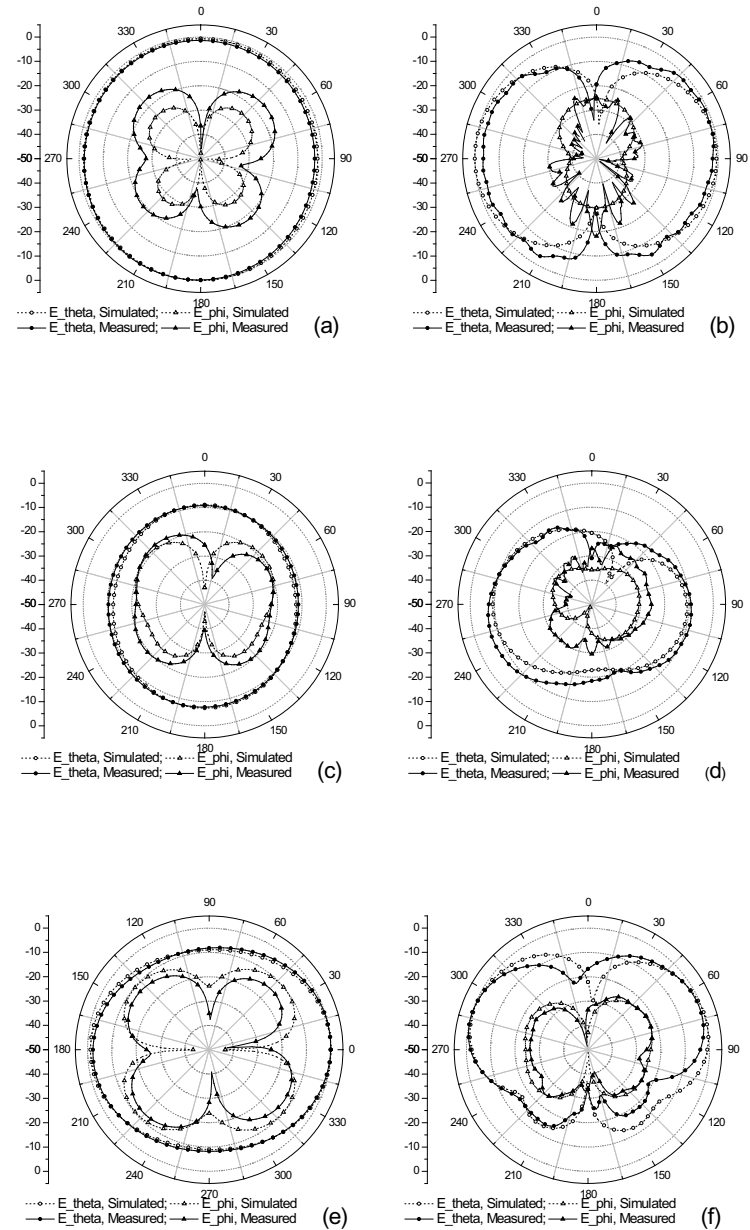

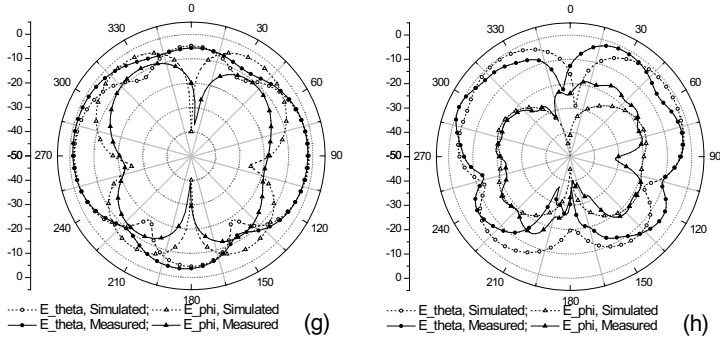

Fig. 8 Simulated and measured radiation patterns of proposed antenna. (a) 3 $\mathrm{GHz}$ in $\mathrm{x}-\mathrm{y}$ plane; (b) $3 \mathrm{GHz}$ in $\mathrm{x}-\mathrm{z}$ plane; (c) $5.5 \mathrm{GHz}$ in $\mathrm{x}-\mathrm{y}$ plane; (d) 5.5 $\mathrm{GHz}$ in $\mathrm{x}-\mathrm{z}$ plane; (e) $7 \mathrm{GHz}$ in $\mathrm{x}-\mathrm{y}$ plane; (f) $7 \mathrm{GHz}$ in $\mathrm{x}-\mathrm{z}$ plane; (g) $10 \mathrm{GHz}$ in $\mathrm{x}-\mathrm{y}$ plane; and (h) $10 \mathrm{GHz}$ in $\mathrm{x}-\mathrm{z}$ plane.

Finally, the simulated and measured peak gains and efficiencies of the antenna are shown in Figs. 9 (a) and (b), respectively. The average antenna gain is about $3.5 \mathrm{dBi}$ over most of the UWB operating frequency range. However, at the notched band, significant reductions in gain and radiation efficiency can be seen. The antenna gain is suppressed from about $3 \mathrm{dBi}$ to $-7.1 \mathrm{dBi}$ and the radiation efficiency is reduced from about $85 \%$ to $8.7 \%$. These phenomena indicate that the meandered ground stubs works effectively to introduce a single band-notched characteristic for the antenna.

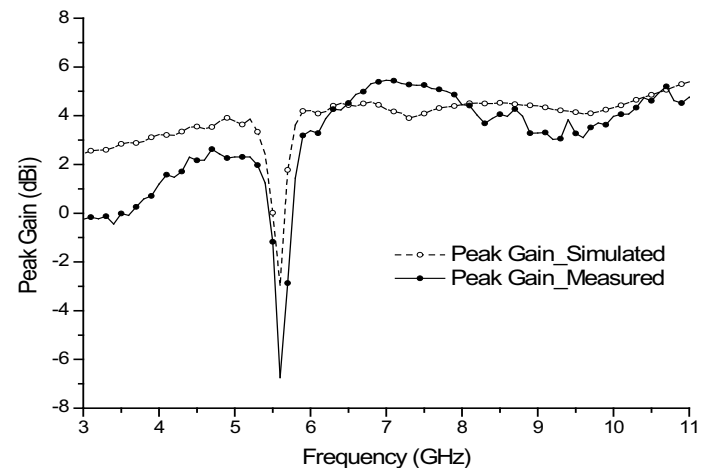

(a)

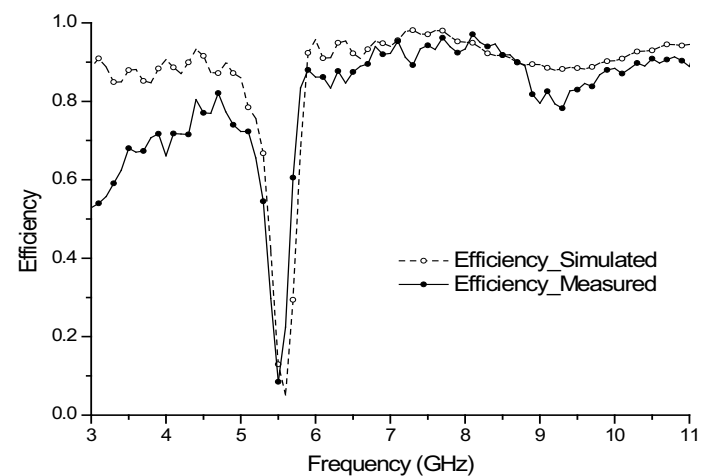

(b)

Fig. 9 Simulated and measured (a) peak gain and (b) efficiency of proposed antenna.

\section{CONCLUSIONS}

In this paper, a pair of meandered ground stubs has been proposed to design single band-notched characteristics for compact planar-monopole UWB antennas. The proposed idea has been used to design a compact UWB antenna. Studies using computer simulation and measurement on the return loss, antenna patterns, peak gains and radiation efficiencies of the UWB antenna have been carried. Results have shown that the antenna has approximately omnidirectional radiation patterns with good band notched performances.

\section{REFERENCES}

[1] "Federal Communications Commission Revision of Part 15 of the Commission's Rules Regarding Ultra-Wideband Transmission Systems," FCC, 2002, First Report and Order FCC, 02.V48.

[2] Availanle on: http://www.fcc.gov/pshs/techtopics/techtopics10.html.

[3] Schantz, Hans, Glenn Wolenec, Edward (Mike) Myszka, "Frequency notched UWB antennas," IEEE Conference on Ultra Wideband Systems and Technologies. Reston, Virginia, Nov, 2003.

[4] K. Kim, Y. Cho, S. Hwang, and S. Park, "Band-notched UWB planar monopole antenna with two parasitic patches," Electron. Lett., vol. 41, no. 14 , pp. $783-785$, Jul. 2005 .

[5] T. G. Ma and S. J. Wu, "Ultrawideband band-notched folded strip monopole antenna," IEEE Trans. Antennas Propag., vol. 55, no. 9, pp. 2473-2479, Sep. 2007.

[6] J. Kim, C. S. Cho and J. W. Lee, "5.2 GHz notched ultra-wideband antenna using slot-type SRR,” Electron. Lett., vol. 42, no. 6, pp. 315 316, Mar. 2006

[7] Y.F. Weng, S.W. Cheung and T.I. Yuk, "An Antenna For UWB and Bluetooth Standards with Band-Notched Characteristic" 2009 IEEE International Conference on Ultra-Wideband (ICUWB), 9-11 September 2009, Vancouver, Canada.

[8] A. Kerkhoff and H. Ling, "Design of a planar monopole antenna for use with ultra-wideband (UWB) having a band-notched characteristic," in IEEE AP/S Int. Symp. Dig., 2003, vol. 1, pp. 830-833.

[9] Y.F. Weng, W.J. Lu, S.W. Cheung and T.I. Yuk, "UWB Antenna with Single or Dual-Band Notched Characteristic for WLAN Band using Meandered Ground Stubs" 2009 Loughborough Antennas \& Propagation Conference, 16-17 November 2009, Loughborough, UK.

[10] S.W. Qu, J.L. Li and Q. Xue, "A Band-Notched Ultrawideband Printed Monopole Antenna," IEEE Antennas and Wireless Progag Lett, vol. 5, pp. 495-498, 2006.

[11] W. J. Lui, C. H. Cheng, Y. Cheng, and H. Zhu, "Compact Frequency notched ultra-wideband microstrip slot antenna with fractal tuning stub," Electron. Lett., vol. 41, no.6, pp.294-296, Mar., 2005.

[12] Y.J. Cho, K.H. Kim, D.H. Choi, S.S. Lee and S.O. Park, "A miniature UWB planar monopole antenna with $5 \mathrm{GHz}$ band-rejection filter," IEEE Trans. Antennas and Propag, vol. 54, issue 5, pp. 1453-1460, Oct, 2005.

[13] Y. Kim and D.-H. Kwon, "CPW-fed planar ultra wideband antenna having a frequency band notch function," Electron. Lett., vol.40, no.7, pp.403-405, Apr.2004

[14] E. Pancera, D. Modotto, A. Locatelli, F.M. Pigozzo and C. De Angelis "Novel Design of UWB Antenna with Band-Notch Capability," European Conference on Wireless Technologies, pp 48-50, Munich, Dec 2007.

[15] S.H. Lee, J.W. Baik and Y.S. Kim, "A COPLANAR WAVEGUIDE FED monopole ultra-wideband antenna having band-notched frequency function by two folded-stripline," Microw. Opt. Tech. Lett., vol. 49, issue 11, pp. 2747-2750, Aug. 2007 